$\begin{gathered}\text { Науковий вісник Нлту України } \\ \text { Scientific Bulletin of UNFU } \\ \text { https://nv.nltu.edu.ua }\end{gathered}$
$\begin{aligned} & \text { https://doi.org/10.15421/40290521 (i) ISSN 1994-7836 (print) } \\ & \text { Article received } 14.05 .2019 \mathrm{p} .\end{aligned}$
$\begin{aligned} & \text { Article accepted 30.05.2019 p. } \\ & \text { ISSN 2519-2477 (online) }\end{aligned}$

I. Р. Ващишак', С. П. Ващишак ${ }^{2}$

${ }^{I}$ Івано-Франківський національний технічний університет нафти і газу, м. Івано-Франківськ, Украӥна

${ }^{2}$ Приватний навчальний заклад Університет Короля Данила, м. Івано-Франківськ, Украӥна

\title{
РЕКУПЕРАТОР НА ПУЛЬСАЦЙНИХ ТЕПЛОВИХ ТРУБКАХ З МІКРОПРОЦЕСОРНИМ УПРАВЛІННЯМ
}

\begin{abstract}
Для забезпечення одночасного провітрювання та опалення приміщень за допомогою системи вентиляції та 3 метою економії енергоносіїв запропоновано розробити конструкцію рекуператора з теплообмінником на пульсаційних теплових трубках. Встановлено, що пульсаційні теплові трубки є простішими, надійнішими і дешевшими за звичайні гнітові теплові трубки за співрозмірної з ними теплової ефективності. Запропоновано як елементи теплообмінника рекуператора застосувати багатовиткові замкнені пульсаційні теплові трубки, які серед інших типів пульсаційних трубок мають найвищу теплову ефективність. Запропоновано застосувати у теплообміннику на пульсаційних теплових трубках керамічні нагрівні елементи, що доповнить систему вентиляції функціями системи опалення. Наведено методику розрахунку теплових та конструктивних параметрів пульсаційних теплових трубок, яка дає змогу отримати оптимальні теплові параметри теплообмінника завдяки зміні конструктивних, або оптимальні конструктивні параметри завдяки зміні теплових. Це дає змогу спроектувати рекуператор системи вентиляції для різних умов експлуатації. 3 метою досягнення повної автономності запропоновано для управління роботою системи вентиляції використати мікропроцесор. Це дасть змогу підтримувати необхідну температуру і рівень чистого повітря у приміщенні залежно від часу доби завдяки зміні режимів роботи електродвигунів вентиляторів та часу нагрівання керамічних нагрівачів.
\end{abstract}

Ключові слова: система вентиляції; система опалення; теплообмінник; теплова ефективність; мікропроцесор.

Вступ. Вентиляція у приміщенні виконує два основних завдання: забезпечення комфортних умов для перебування людей та утримання його конструкцій у належному стані. Останнім часом енергоефективні механічні системи вентиляції з рекуператорами почали використовувати і як системи опалення приміщень. Застосування рекуператорів дає змогу внаслідок незначного здорожчання системи вентиляції істотно зменшити витрати енергоносіїв.

Сьогодні відомо кілька видів рекуператорів: роторні, камерні, $з$ проміжним теплоносієм, ентальпійні, пластинчасті (Mileikovskyi \& Kotelkov, 2018). Всі вони мають значні розміри, є дорогими та складними в обслуговуванні. На нашу думку, найоптимальнішим за критерієм енергоефективності є застосування рекуператорів 3 максимально можливою тепловою ефективністю та мінімально можливими технічним обслуговуванням i ціною. Цим умовам відповідають рекуператори на пульсаційних теплових трубках із мікропроцесорним управлінням швидкістю повітряних потоків та ступенем їх додаткового нагрівання. Застосування таких рекуператорів дасть змогу отримати енергоефективну систему вентиляції з функціями системи опалення, істотно підвищити термін іiї експлуатації та за відповід- ним алгоритмом змінювати температурний режим у приміщенні в широких межах.

Мета дослідження - розробити основні технічні рішення для створення дешевих, простих в обслуговуванні та надійних рекуператорів на пульсаційних теплових трубках із високою тепловою ефективністю, які працюватимуть у складі програмно-керованої системи вентиляції та опалення приміщення.

Викладення основного матеріалу. Для побудови рекуператора 3 високою тепловою ефективністю доцільно використати теплові трубки, як теплообмінники 3 найбільшою тепловою ефективністю з усіх теплообмінних апаратів. Окрім цього, теплові трубки мають високу надійність і тривалі терміни експлуатації (Vashchyshak \& Dotsenko, 2018). Однак є деякі обмеження. По-перше, тепловій трубці важко надати форму, що максимально омивається повітряними потоками. По-друге, такі трубки, внаслідок значної маси й об'єму, надійно запускаються за певного рівня теплової потужності, який, у випадку повітряних потоків, є досить низьким. По-третє, самі трубки та їх кріплення в рекуператорі займають багато місця. По-четверте, вартість теплових трубок через складність конструкції $є$ досить високою, що істотно обмежує їх використання. Тому

Інформація про авторів:

Ващишак Ірина Романівна, канд. техн. наук, доцент, кафедра енергетичного менеджменту та технічної діагностики. Email: savchyn.ira@gmail.com; https://orcid.org/0000-0002-9078-6726

Ващишак Сергій Петрович, канд. техн. наук, доцент, кафедра інформаційних технологій та програмної інженерії. Email: serhii.vashchyshak@gmail.com; https://orcid.org/0000-0002-1753-1540

Цитування за ДСту: Ващишак І. Р., Ващишак С. П. Рекуператор на пульсаційних теплових трубках з мікропроцесорним управлінням. Науковий вісник НлтУ України. 2019, т. 29, № 5. С. 107-110.

Citation APA: Vashchyshak, I. R., \& Vashchyshak, S. P. (2019). Heat Exchanger on Pulsation heat Pipes with Microprocessor Control. Scientific Bulletin of UNFU, 29(5), 107-110. https://doi.org/10.15421/40290521 
завданням $\epsilon$ створення рекуператора 3 тепловою ефективністю на рівні теплових трубок, але меншого за розмірами, простішого за конструкцією та дешевшого.

Для цього запропоновано використати один 3 видів теплових трубок - пульсаційні теплові трубки (ПТТ). На відміну від класичних теплових трубок $з$ пористим гнітом, рух теплоносія у ПТТ здійснюється не тільки завдяки капілярним силам, силам тяжіння та інерції, але й механічної дії зростаючих парових бульбашок. ПТТ має просту конструкцію - це тонкостінна металева герметизована трубка малого діаметра, частково заповнена теплоносієм, з якої повністю видалено повітря. Основною відмінністю ПТТ від класичної теплової трубки $є$ наявність вигинів (витків), за допомогою яких ПТТ може мати значну довжину.

Працює ПТТ так. Після герметизації під дією капілярних сил у ПТТ формуються парові та рідинні пробки (снаряди), які довільно розподіляються по всій іiі довжині. Після підводу теплового потоку до зони нагріву, в ній починається процес пароутворення, завдяки якому в ПТТ змінюється розподіл паровмісту, що призводить до виникнення градієнта тиску, під дією якого починається пульсуючий рух теплоносія із зони нагріву через зону транспорту в зону конденсації, що супроводжується перенесенням теплової енергії. Переміщення певної частини теплоносія із зони нагріву в зону конденсації знову змінює розподіл паровмісту в ПТТ, що призводить до зміни градієнта тиску, під дією якого теплоносій повертається в зону нагріву. Отже, завдяки взаємопов'язаним коливанням паровмісту та тиску в ПТТ підтримуються автоколивання двофазного потоку теплоносія (Nagvase \& Pachghare, 2013). Завдяки тому, що процеси утворення, відриву і переміщення парових снарядів відбуваються за короткі проміжки часу, правильно працююча ППТ може передавати значну кількість теплоти. Тому така конструкція має високу теплопровідність і іï можна використовувати як теплообмінник у рекуператорі.

Залежно від конструкції розрізняють три основні типи ПТТ (Mohod et al., 2013): незамкнені, замкнені, ПТТ 3 контрольними клапанами. Під час проектування рекуператора вибрано замкнені ПТТ, оскільки вони є найефективнішими 3 усіх типів, бо працюють за будьякої орієнтації в просторі, але найкраще - за вертикального розміщення. За рахунок малого діаметра капілярів їх можна виготовити значну кількість, що збільшує площу контакту ПТТ з потоками повітря, зменшує розміри і підвищує теплову ефективність рекуператора. Також процес перенесення тепла паровими снарядами $є$ ефективнішим за просте випаровування, що застосовують у звичайних теплових трубках.

Щоб система вентиляції виконувала функції системи опалення, запропоновано в нижній частині зони нагріву рекуператора встановити керамічні нагрівачі, які, за командою $з$ мікропроцесора, будуть додатково підігрівати ПТТ для підвищення температури повітря, що подається у приміщення. Для розрахунку параметрів рекуператора на ПТТ необхідно задатись температурами всередині $t_{\text {поч }}$ та зовні $t_{\text {кін }}$ приміщення, площею вентильованих приміщень $S_{\text {пим }}$, їх висотою $H$, матеріалом капіляра та вибрати теплоносій.

Згідно з вимогами (DBN V.2.5-67, 2013), максимально необхідний об'єм чистого повітря дорівнює $3 \mathrm{~m}^{3} /$ год на $1 \mathrm{~m}^{2}$ площі житлового приміщення вдень та $0,6 \mathrm{~m}^{3} /$ год на $1 \mathrm{~m}^{2}$ площі житлового приміщення вночі. Для виконання цих вимог вентиляція повинна забезпечувати денний повітрообмін ( $\mathrm{m}^{3} /$ год), що дорівнює

$$
L_{\partial}=S_{\text {прим }} \cdot H \cdot 3,
$$

та нічний повітрообмін, що дорівнює

$$
L_{H}=S_{\text {прим }} \cdot H \cdot 0,6 \text {. }
$$

Згідно $з$ методикою, наведеною в (Vashchyshak \& Dotsenko, 2018), витрати на нагрівання зовнішнього повітря до заданої температури (у Вт) знаходимо з виразу

$$
Q_{\max }=0,335 \cdot L \cdot\left(t_{\text {поч }}-t_{\text {кін }}\right) .
$$

Теплоносій вибираємо 3 погляду на його максимальну ефективність

$$
N=\frac{\rho_{P} \cdot \sigma \cdot r}{\mu_{P}},
$$

де: $\rho_{P}$ - густина теплоносія, кг $/ \mathrm{M}^{3} ; \sigma-$ коефіцієнт поверхневого натягу теплоносія, H/м; $r$ - теплота пароутворення теплоносія, Дж/кг; $\mu_{P}-$ коефіцієнт динамічної в'язкості теплоносія, Па·с.

Як матеріал капіляру ПТТ вибираємо мідь 3 коефіцієнтом ефективної теплопровідності $\lambda=390 \mathrm{BT} / \mathrm{M}^{\circ}{ }^{\circ} \mathrm{C}$. Критичне значення внутрішнього діаметра капіляру (в м) знаходимо за формулою

$$
d_{6 H} \leq 2 \cdot \sqrt{\frac{\sigma}{g \cdot\left(\rho_{p}-\rho_{n}\right)}},
$$

де $\sigma$ - коефіцієнт поверхневого натягу теплоносія, H/м; $g$ - прискорення вільного падіння, м/ $\mathrm{c}^{2} ; \rho_{p}, \rho_{n}-$ густина рідкої та парової фази теплоносія відповідно,

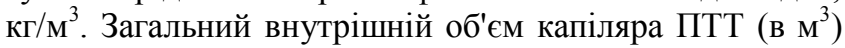
становить

$$
V_{3}=\frac{\pi \cdot d_{6 H}^{2} \cdot L_{\text {sum }} \cdot n_{\text {sum }}}{4}
$$

де: $L_{\text {вum }}$ - загальна довжина одного витка ПТТ, м; $n_{\text {вum }}$ - кількість витків ПТТ у змійовику рекуператора.

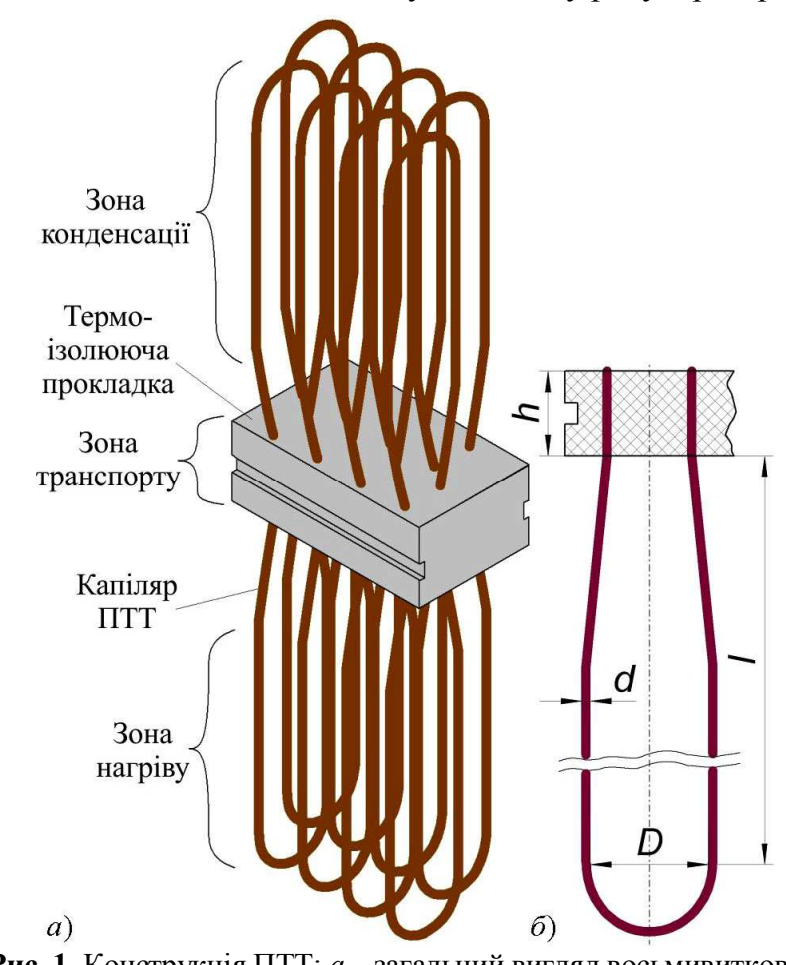

Рис. 1. Конструкція ПТТ: $a$ - загальний вигляд восьмивиткової ПТТ, $\sigma$ - розрахункова модель ПТТ

Згідно 3 (Vashchyshak \& Dotsenko, 2018), оптимальна кількість витків однієї замкнутої ПТТ дорівнює 8 
(рис. 1,a), а коефіцієнт заповнення капіляра теплоносієм - $50 \%$. 3 рис. 1,б визначаємо площу поверхні теплообміну одного витка ПТТ (в м $\left.{ }^{2}\right)$ за формулою

$$
S_{\text {витка } 3 H}=L_{\text {вит }} \cdot \pi \cdot d=(\pi \cdot D+4 \cdot l+2 \cdot h) \cdot \pi \cdot d .
$$

Звідки довжина та площа всіх витків ПТТ рекуператора становитимуть

$$
\begin{gathered}
L_{\text {вит ПтT }}=(\pi \cdot D+4 \cdot l+2 \cdot h) \cdot n_{\text {вит }}, \\
S_{\text {вит ПТт }}=S_{\text {витка } 3 H} \cdot n_{\text {вит }} .
\end{gathered}
$$

Падіння температури в зонах ПТТ (див. рис. 1) розраховуємо з виразів (Alekseyk, 2015):

$$
\Delta t_{3 H}=\frac{q_{3 H}}{\alpha_{3 H c}}, \Delta t_{3 K}=\frac{q_{3 K}}{\alpha_{3 K c}},
$$

де: $q_{3 н}$ та $q_{3 \kappa}$ - густини теплових потоків у зонах нагріву та конденсації відповідно, Вт/м² (визначаються 3 врахуванням додаткового нагрівання та теплової ефективності ПТТ); $\alpha_{3 H c}$ та $\alpha_{3 К c}-$ середні значення коефіцієнтів тепловіддачі в зонах нагріву та конденсації, відповідно, Вт $/ \mathrm{M}^{2} \cdot \mathrm{K}$ (визначаються згідно 3 методикою) (Ivanovskii et al., 1980).

Після цього, враховуючи товщину та матеріал стінки капіляра, розраховуємо перепади температури за товщиною стінок ПТТ (Ivanovskii et al., 1980) за формулами:

$$
\begin{aligned}
& \Delta t_{3 H}^{c m}=\left(t_{c m 1}-t_{c m 2}\right)=\frac{Q_{3 H} \cdot h_{c m}}{\lambda}, \\
& \Delta t_{3 K}^{c m}=\left(t_{c m 1}-t_{c m 2}\right)=\frac{Q_{3 K} \cdot h_{c m}}{\lambda},
\end{aligned}
$$

де: $t_{c m 1}, t_{c m 2}-$ температури всередині та зовні стінки відповідно, К; $h_{\text {ст }}$ - товщина стінки капіляра, м; $Q_{3 H}$, $Q_{3 \kappa}$ - теплові потоки відповідно в зонах нагріву та конденсації, Вт.

Загальний перепад температур між зонами нагріву та конденсації ПТТ знаходимо за формулами (Alekseyk, 2015):

$$
\Delta t=\Delta t_{3 H}+\Delta t_{3 K}+\Delta t_{3 H}^{c m}+\Delta t_{3 K}^{c m} .
$$

Ефективність ПТТ рекуператора за температури оцінюємо з виразу

$$
\eta_{t}=100-\frac{\Delta t \cdot 100}{t_{\text {nou }}} .
$$

Термічний опір ПТТ рекуператора знаходимо за формулою

$$
R=\frac{\Delta t}{Q_{\max }} .
$$

Розрахунок термічного опору ПТТ варто повторювати, кожен раз корегуючи значення довжин зон нагріву та конденсації та кількості витків ПТТ, до досягнення мінімального його значення.

Еквівалентну теплопровідність ПТТ визначаємо 3 виразу (Alekseyk, 2015)

$$
\lambda_{\text {eкв }}=\frac{Q_{\max } \cdot L_{e \phi}}{\Delta t \cdot S_{K}},
$$

де: $L_{e \phi}$ - ефективна довжина ПТТ, яка дорівнює півсумі довжин зон нагріву та конденсації, м; $S_{K}$ - площа поперечного перерізу капіляра ПТТ, м $^{2}$.

Будову рекуператора 3 теплообмінником на ПТТ зображено на рис. 2. Теплообмінник складається 3 секцій восьмивиткових ПТТ 1, з'єднаних між собою послідовно та паралельно. Керамічні нагрівачі 2 з керамічними вставками 3 слугують для додаткового підігріву ПТТ. Уся конструкція поміщена у термоізолювальний кожух 4.

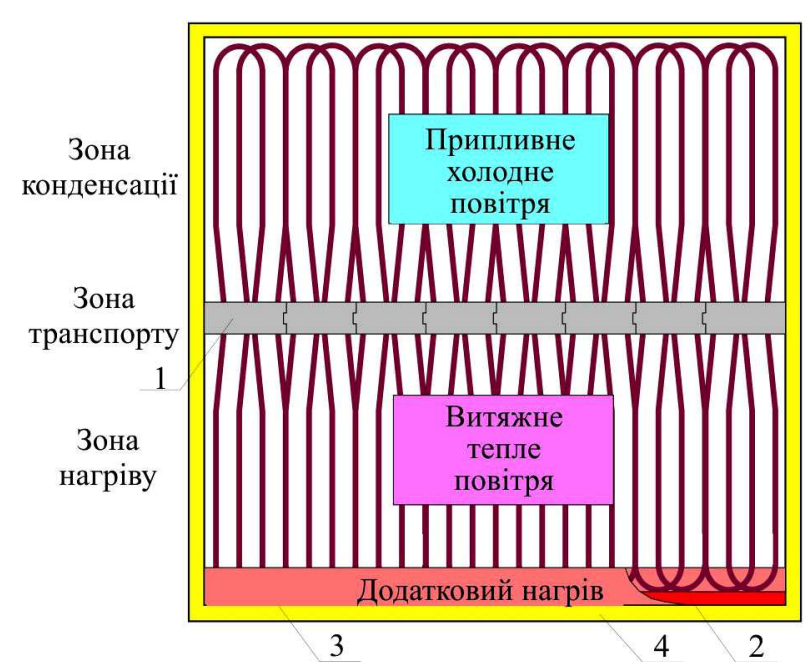

Рис. 2. Будова рекуператора з теплообмінником на багатовиткових ПТТ

Працює рекуператор подальшим чином. Тепле витяжне повітря омиває витки вертикально розміщеної багатовиткової замкненої ПТТ у зоні нагріву, віддаючи їм значну частину теплової енергії. Завдяки руху парових снарядів ця енергія надходить в зону конденсації і передається потокові холодного повітря, яке поступає ззовні у приміщення. Зона транспорту розміщена в термоізоляційній прокладці, яка поділяє рекуператор на дві камери (нагрівальну та конденсаційну). Ця прокладка запобігає втраті теплової енергії під час транспортування теплового потоку та утворення конденсату. Завдяки додатковому нагріву ПТТ керамічними нагрівачами енергія теплового потоку збільшується, що підвищує температуру припливного повітря. Регулюючи час включення керамічних нагрівачів, можна встановлювати необхідну температуру в приміщеннях. У цьому випадку систему вентиляції можна використовувати як систему опалення.

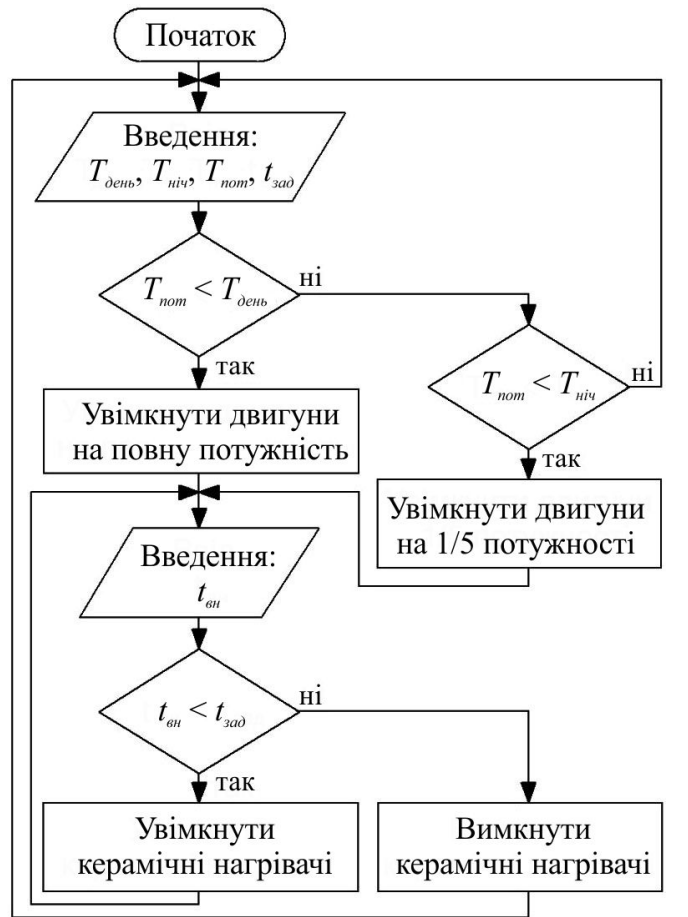

Рис. 3. Алгоритм роботи МП системи вентиляції та опалення

Окрім рекуператора з керамічними нагрівачами, система вентиляції з функціями системи опалення повинна мати два вентилятори та давач температури всередині 
приміщення. Для керування нею доцільно застосувати мікропроцесор, який здійснюватиме фазо-імпульсне управління обертами двигунів вентиляторів та широтноімпульсне управління керамічними нагрівачами.

Алгоритм роботи мікропроцесора наведено на рис. 3 . Працює мікропроцесор подальшим чином. 3 клавіатури вводиться денний і нічний час доби $T_{\text {ден }}, T_{\text {ніч}}$, та задана

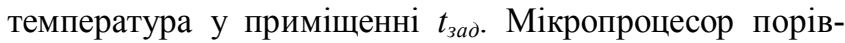
нює поточний час $T_{\text {nот }} 3 T_{\text {ден }} \mathrm{i}$, якщо пора доби денна, то двигуни вентиляторів вмикаються на повну потужність для забезпечення повітрообміну рівним $3 \mathrm{~m}^{3} /$ год на $1 \mathrm{~m}^{2}$ площі приміщення. Потім порівнюється температура у приміщенні $t_{6 н} 3 t_{\text {зад }}$, i, якщо вона менша, то вмикаються керамічні нагрівачі. Вони вимкнуться, коли $t_{6 н}$

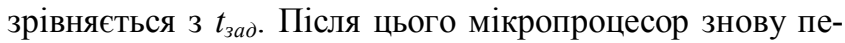
ревірятиме час доби і якщо час нічний, то двигуни вентиляторів будуть переведені на 20 \% потужності для забезпечення повітрообміну $0,6 \mathrm{~m}^{3} /$ год на $1 \mathrm{~m}^{2}$ площі при-

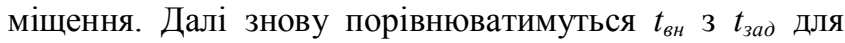
ввімкнення та вимкнення керамічних нагрівачів. Після цього цикл роботи повторюватиметься. Такий режим роботи забезпечує системі вентиляції і опалення повну автономність.

\section{Висновки:}

1. Основною перевагою рекуператора є його висока енергоефективність та низька вартість завдяки застосуванню теплообмінника на ПТТ.

2. Рекуператор на ПТТ є пасивним пристроєм, що не має рухомих частин. Завдяки своїй конструкції він має високу надійність, простий в експлуатації й обслуговуванні.

3. Наведена методика розрахунку ПТТ дає змогу отримати оптимальні теплові параметри теплообмінника зав- дяки незначній зміні конструктивних або оптимальних конструктивних завдяки незначній зміні теплових. Це дає змогу проектувати рекуператори на ПТТ для різних умов експлуатації.

4. Алгоритм роботи мікропроцесора дає змогу підтримувати необхідну температуру і рівень чистого повітря у приміщенні залежно від часу доби завдяки зміні режимів роботи електродвигунів вентиляторів та часу нагрівання керамічних нагрівачів.

\section{Перелік використаних джерел}

Alekseyk, E. S. (2015). Vplyv rezhymnykh ta heometrychnykh faktoriv na teploperedaiuchi kharakterystyky pulsatsiinykh teplovykh trub. Candidate Dissertation for Technical Sciences (05.14.06 Technical Thermophysics and Industrial Thermal Power Engineering). Kyiv: NTUU "KPI", 167 p. [In Ukrainian].

Ivanovskii, M. N., et al. (1980). Tekhnologicheskie osnovy teplovykh trub. Moscow: Atomizdat, 160 p. [In Russian].

Mileikovskyi, V. O., \& Kotelkov, L. M. (2018). Ventyliatsiia indyvidualnoho zhytlovoho budynku. Dnieper: Seredniak T. K., 156 p. [In Ukrainian].

Mohod, T. R., et al. (2013). Design Parameters of Pulsating / Oscillating Heat Pipe. International Journal of Engineering and Advanced Technology, 2(4), 461-463.

Nagvase, S. Y., \& Pachghare, P. R. (2013). Parameters Affecting the Functioning of Close Loop Pulsating Heat Pipe. Research Journal of Engineering Sciences, 2, 35-39.

Vashchyshak, I. R., \& Dotsenko, Ye. R. (2018). Proektuvannia rekuperatora na pulsatsiinykh teplovykh trubkakh dlia obiektiv naftohazovoho kompleksu. Naukovyi visnyk IFNTUNH, 2(45), 16-23. [In Ukrainian].

DBN V.2.5-67:2013. Opalennia, ventyliatsiia ta kondytsionuvannia, from 01 Jan 2014. Kyiv, 35 p. [In Ukrainian].

I. R. Vashchyshak1, S. P. Vashchyshak ${ }^{2}$

${ }^{1}$ Ivano-Frankivsk National Technical University of Oil and Gas, Ivano-Frankivsk, Ukraine

${ }^{2}$ Private Higher King Daniel of Galicia Ivano-Frankivsk University of Law, Ivano-Frankivsk, Ukraine

\section{HEAT EXCHANGER ON PULSATION HEAT PIPES WITH MICROPROCESSOR CONTROL}

First of all ventilation in room provides a comfortable environment for people. Energy-efficient mechanical ventilation systems with heat exchangers are recently used as heating systems. Providing ventilation and space heating by one small-sized system requires new technical solutions. It is possible to create such a system on the basis of modern ventilation systems with air heat exchangers. A heat exchanger design with a heat transfer device based on multi-turn closed pulsating heat pipes for ventilation of premises has been proposed. This heat exchanger is characterized by a high thermal efficiency and small overall with classic heat pipes. Ceramic electric heaters are proposed to be installed in the lower part of the heat exchanger for space heating. These heaters will increase the power of the heat flow received by the pulsating heat pipes of the heat exchanger from the warm air that is removed from the room. The heat exchanger will increase the temperature of fresh air supply to the level required in the room. The technical solutions allow using the ventilation system with a heat exchanger for space heating. Thus, the proposed heat exchanger with a heat transfer device based on pulsating heat pipes and ceramic heaters, due to the lack of moving parts, will be of high reliability, low cost, easy to operate and maintain. A method for calculating multi-turn closed pulsation heat pipes of a heat exchanger is proposed. The given method allows obtaining optimal thermal parameters of the heat exchanger due to changes in design or optimal design parameters due to changes in heating ones. This allows designing the heat exchanger of the ventilation system for any operating conditions. Microprocessor control is used for the ventilation system controlling. The processor maintains the required temperature and level of clean air in the room by changing the operating modes of the fan motors and the heating time of the ceramic heaters. The fan motors are driven by the phase-pulse method. Ceramic heaters are driven by pulse width modulation. An algorithm for the operation of the processor has been compiled, which allows fully autonomous operation of the ventilation system both in the room ventilation mode and in the heating mode.

Keywords: ventilation system; heating system; heat exchanger; thermal efficiency; microprocessor. 